\title{
Biological Reduction of a U(V)-Organic Ligand Complex
}

Margaux Molinas, Radmila Faizova, Ashley Brown, Jurij Galanzew, Bianca Schacherl, Barbora Bartova, Karin L. Meibom, Tonya Vitova, Marinella Mazzanti, and Rizlan Bernier-Latmani*

Cite This: https://dx.doi.org/10.1021/acs.est.0c06633

Read Online

ABSTRACT: Metal-reducing microorganisms such as Shewanella oneidensis MR-1 reduce highly soluble species of hexavalent uranyl (U(VI)) to less mobile tetravalent uranium (U(IV)) compounds. The biologically mediated immobilization of $\mathrm{U}(\mathrm{VI})$ is being considered for the remediation of $U$ contamination. However, the mechanistic underpinnings of biological U(VI) reduction remain unresolved. It has become clear that a first electron transfer occurs to form pentavalent $(\mathrm{U}(\mathrm{V}))$ intermediates, but it has not been definitively established whether a second one-electron transfer can occur or if disproportionation of $\mathrm{U}(\mathrm{V})$ is required. Here, we utilize the unusual properties of dpaea ${ }^{2-}$ ((dpaeaH $\mathrm{H}_{2}=$ bis(pyridyl-6-methyl-2-carboxylate)-ethylamine $\left.)\right)$, a ligand forming a stable soluble aqueous complex with $\mathrm{U}(\mathrm{V})$, and investigate the reduction of $\mathrm{U}(\mathrm{VI})$-dpaea and $\mathrm{U}(\mathrm{V})$-dpaea by $S$. oneidensis MR-1. We

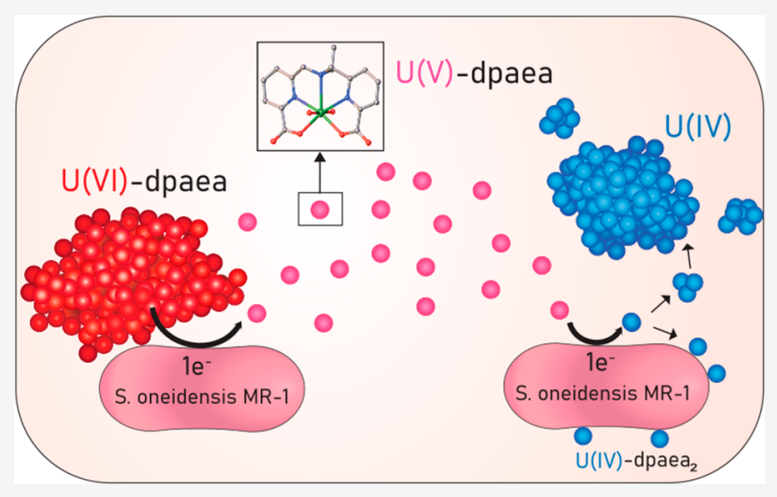
establish $U$ speciation through time by separating $U(V I)$ from $U(I V)$ by ion exchange chromatography and characterize the reaction end-products using $\mathrm{U} \mathrm{M}_{4}$-edge high resolution X-ray absorption nearedge structure (HR-XANES) spectroscopy. We document the reduction of solid phase U(VI)-dpaea to aqueous U(V)-dpaea but, most importantly, demonstrate that of $\mathrm{U}(\mathrm{V})$-dpaea to $\mathrm{U}(\mathrm{IV})$. This work establishes the potential for biological reduction of $\mathrm{U}(\mathrm{V})$ bound to a stabilizing ligand. Thus, further work is warranted to investigate the possible persistence of $U(V)-$ organic complexes followed by their bioreduction in environmental systems.

KEYWORDS: pentavalent uranium, uranium reduction, electron transfer, disproportionation, Shewanella, bioremediation, HERFD-XANES, scanning transmission electron microscopy (STEM)

\section{INTRODUCTION}

The environmental behavior of uranium $(\mathrm{U})$ is driven by its redox chemistry. In its oxidized cationic form, $\mathrm{U}(\mathrm{VI})\left(\mathrm{UO}_{2}{ }^{2+}\right)$, it is highly soluble and mobile when forming stable complexes with appropriate ligands (e.g., carbonate), ${ }^{1,2}$ whereas in its reduced form, $\mathrm{U}(\mathrm{IV})$, it tends to precipitate as crystalline $\mathrm{U}$ oxides $^{3}$ or in an amorphous $U$ phase. ${ }^{4}$ These physicochemical properties have been proposed for the remediation of Ucontaminated areas by immobilizing $U$ as $U(I V) .{ }^{5}$ The transition from $\mathrm{U}(\mathrm{VI})$ to $\mathrm{U}(\mathrm{IV})$ occurs via the transfer of two electrons by a microorganism, ${ }^{3,4,6-9}$ such as dissimilatory metal-reducing bacteria (DMRB) Geobacter sulfurreducens ${ }^{3}$ or Shewanella oneidensis MR-1, 4,8,9 or a reduced mineral phase, such as ferrous iron-bearing minerals. ${ }^{10-13}$ In both mineral and biological cases, a pentavalent $\mathrm{U}(\mathrm{V})$ intermediate has been shown to form following a one-electron transfer to the U(VI) moiety. ${ }^{14-22}$ Furthermore, U(V) appears to persist under certain environmentally relevant conditions; ${ }^{14,15}$ however, it remains challenging to detect it, due to its sensitivity to oxidation and its ability to undergo rapid disproportionation to $\mathrm{U}(\mathrm{VI})$ and $\mathrm{U}(\mathrm{IV})$, through the interaction of two uranyl(V) cations (i.e., cation-cation interaction, CCI). ${ }^{23}$
If the biological formation of $\mathrm{U}(\mathrm{V})$ has been documented repeatedly as the result of a one-electron transfer from bacteria to $\mathrm{U}(\mathrm{VI})$, the transformation of $\mathrm{U}(\mathrm{V})$ to $\mathrm{U}(\mathrm{IV})$ has yet to be clarified. Indeed, it has been suggested in multiple studies that $\operatorname{uranyl}(\mathrm{V})$ forms and disproportionates to uranyl(VI) ion and a $\mathrm{U}(\mathrm{IV})$ species. $^{18-22}$ In those studies, U(VI) reduction was monitored in a carbonate-rich buffer in the presence of Geobacter sulfurreducens, ${ }^{18,21}$ Shewanella oneidensis MR- $1^{22}$ or a microbial biofilm. ${ }^{19}$ Direct experimental evidence of uranyl(V) arose from EXAFS analysis of the incubation supernatants of G. sulfurreducens, ${ }^{18}$ and recently from $\mathrm{M}_{4}$-edge HR-XANES on cell suspensions of $S$. oneidensis MR-1. ${ }^{22}$ As for the second step of the biological reduction, these studies support the disproportionation of uranyl(V), which leads to $U(V I)$ and $\mathrm{U}(\mathrm{IV})$. In fact, Renshaw et al. justify uranyl(V) disproportio-

Received: October 2, 2020

Revised: February 24, 2021

Accepted: March 1, 2021 
nation in their system by substituting stable $\mathrm{Np}(\mathrm{V})$ to $\mathrm{U}(\mathrm{V})$ in their experiment and reporting its lack of reduction. ${ }^{18}$ By analogy, the authors conclude that $\mathrm{U}(\mathrm{V})$ would not either, and thus that $\mathrm{U}(\mathrm{V})$ disproportionates to form $\mathrm{U}(\mathrm{IV})$. Such observations were later supported by Jones et al. ${ }^{21}$ and more recently by Vettese et al., ${ }^{22}$ who report a sawtooth profile for uranyl(VI) fluorescence in cell suspensions of G. sulfurreducens and $S$. oneidensis MR-1, respectively. ${ }^{21,22}$ The repeated increases in the U(VI) fluorescence intensity, forming the sawtooth profile, are interpreted as $\mathrm{U}(\mathrm{V})$ disproportionation releasing uranyl(VI).

However, these experiments were conducted in carbonaterich buffer ${ }^{18,22}$ in which the disproportionation of $U(V)$ is rapid at circumneutral $\mathrm{pH}^{24}$ In the environment, biological $\mathrm{U}(\mathrm{VI})$ reduction often occurs in organic-rich environments. ${ }^{25,26}$ In light of the fact that other pentavalent actinides, such as $\mathrm{Np}(\mathrm{V})$ and $\mathrm{Pu}(\mathrm{V})$, are reduced to $\mathrm{Np}(\mathrm{IV})^{27}$ and $\mathrm{Pu}(\mathrm{IV})^{28}$ by $\mathrm{S}$. oneidensis, stabilization of $\mathrm{U}(\mathrm{V})$ by organic ligands may allow the direct biological reduction of $U(V)$ to U(IV).

In order to fully characterize the mechanism of biological transformation of $U(V)$ to $U(I V)$, we sought direct evidence of the biological reduction of $\mathrm{U}(\mathrm{V})$ by $S$. oneidensis MR-1, using an original approach - the stabilization of soluble $U(V)$ with the novel ligand, dpaea ${ }^{2-}\left(\mathrm{dpaeaH}_{2}=\right.$ bis(pyridyl-6-methyl-2carboxylate)-ethylamine). Dpaea belongs to the class of aminocarboxylate ligands, characterized by one or more nitrogen atom(s) bonded to a carboxylic group via a carbon atom. These ligands have the propensity to chelate metal ions (such as $\mathrm{Fe}^{3+}, \mathrm{Cu}^{2+}, \mathrm{Zn}^{2+}$ ). ${ }^{29}$ Dpaea contains the pyridinecarboxylate metal-binding groups also found in dipicolinic acid. Aminocarboxylate ligands are found naturally in the environment. In fact, they are produced as dipicolinic acid in bacterial endospores, $^{30}$ or nicotianamide in gramineous plants. ${ }^{31}$ In addition, because of their chelation potential, they are applied to remediate metal-contaminated sites (for instance ethylenediaminetetraacetic (EDTA), nitrilotriacetic acid (NTA), ethylenediamine- $N, N^{\prime}$-disuccinic acid (EEDS)), ${ }^{32}$ or support radionuclide extraction in nuclear wastes (for instance, diethylenetriaminepentaacetic acid DTPA). ${ }^{33-36}$

The two goals of this work were to confirm that $U(V)$ forms as a pathway intermediate in the presence of complexing ligands such as dpaea and to establish whether $\mathrm{U}(\mathrm{V})$-dpaea undergoes further biological reduction to $U(I V)$. We note that direct reduction of the $\mathrm{U}(\mathrm{V})$-dpaea complex by chemical reagents has been recently observed by some of the authors in both organic solvents and in water affording monometallic $\left(\left[\mathrm{U}^{\mathrm{IV}}(\right.\right.$ dpaea $)(\mathrm{OBpin})_{2}($ py $\left.)\right]$ and trimetallic $\left(\left[\mathrm{Na}\left(\mathrm{H}_{2} \mathrm{O}\right)_{5}\{\mathrm{U}\right.\right.$ $($ dpaea $\left.\left.)\}_{3}(\mu-\mathrm{O})_{2}(\mu-\mathrm{OH})\left(\mu_{3}-\mathrm{SO}_{3}\right)\right]\right)$ complexes, respectively. ${ }^{37}$ Previously reported complexes of dpaea with uranium include $\mathrm{U}(\mathrm{VI})$-dpaea $\left(\left[\mathrm{UO}_{2}(\right.\right.$ dpaea $\left.\left.)\right]\right), \mathrm{U}(\mathrm{V})$-dpaea $([\mathrm{K}$ (2.2.2.crypt)][ $\mathrm{UO}_{2}($ dpaea $\left.\left.)\right]\right), \mathrm{U}(\mathrm{IV})-$ dpaea $\left(\mathrm{U}(\text { dpaea })_{2}\right)^{38,37}$ and the trinuclear uranium(IV) $\mu$-oxo/hydroxo bridged cluster $\left[\mathrm{Na}\left(\mathrm{H}_{2} \mathrm{O}\right)_{5}\{\mathrm{U}(\text { dpaea })\}_{3}(\mu-\mathrm{O})_{2}(\mu-\mathrm{OH})\left(\mu_{3}-\mathrm{SO}_{3}\right)\right]$ obtained from the chemical reduction of $\mathrm{U}(\mathrm{VI})-$ and $\mathrm{U}(\mathrm{V})$-dpaea in water. The $\mathrm{U}(\mathrm{V})$-dpaea complex is stable and soluble in water at $\mathrm{pH} \mathrm{7,} \mathrm{allowing} \mathrm{for} \mathrm{the} \mathrm{persistence} \mathrm{of} \mathrm{the} \mathrm{ordinarily} \mathrm{transient}$ pentavalent species. ${ }^{38}$ Here, we monitored $U$ oxidation state through time using a combination of spectroscopic, spectrophotometric, and separation techniques. We report the reduction of $\mathrm{U}(\mathrm{VI})$-dpaea to $\operatorname{uranyl}(\mathrm{V})$-dpaea, and observe the further reduction to a solid-phase, noncrystalline U(IV) product. Hence, we suggest that the biological reduction of
$\mathrm{U}(\mathrm{VI})$-dpaea occurs via two successive one-electron transfers, rather than via disproportionation of the $U(V)-d p a e a$ intermediate. The reaction proceeds as follows: (i) $\mathrm{U}(\mathrm{VI})-$ dpaea $_{(\mathrm{s})}$ to $\mathrm{U}(\mathrm{V})-$ dpaea $_{(\mathrm{aq})}$, and then (ii) $\mathrm{U}(\mathrm{V})-$ dpaea $_{(\mathrm{aq})}$ to noncrystalline $U(I V)$ and organic complexes of $U(I V)_{(s)}$.

\section{EXPERIMENTAL METHODS}

Strain and Growth Conditions. Details of strain growth and conditions are described in the Supporting Information (Text S1).

Resting Cells Experiments. Reduction of $U(V I)-$ dpaea. All manipulations were performed inside a nitrogen-atmosphere anaerobic chamber (MBraun, Germany), with $\mathrm{O}_{2}<0.1$ ppm. S. oneidensis MR-1 was incubated, under non-growth conditions, in anoxic modified WLP medium (SI Table S1) in the presence of solid phase $\mathrm{U}(\mathrm{VI})-$ dpaea $\left(\left[\mathrm{UO}_{2}(\right.\right.$ dpaea $\left.)\right] \mathrm{MW}$ $\left.=583 \mathrm{~g} \cdot \mathrm{mol}^{-1}\right)$ at an equivalent aqueous concentrations of 2.5 $\mathrm{mM}$, and synthesized as previously described, ${ }^{38}$ along with 20 $\mathrm{mM}$ of lactate as the electron donor. The starting $\mathrm{OD}_{600}$ of the incubations was measured to be 1 . The incubations were maintained in the dark at room temperature, inside the anaerobic chamber. At several time points, an entire culture was sacrificed for analysis purposes. Solid phase $U$ was separated by centrifugation $(10 \mathrm{~min}$ at $12100 \mathrm{~g})$ and the supernatant was further filtered through $0.2 \mu \mathrm{m}$ PTFE filters (Whatman, Maidstone, United Kingdom). Aliquots of the filtered supernatant were saved for U concentration determination and for HR-XANES measurements. In the latter case, the supernatant and the solid phase were instantaneously frozen in the glovebox with a cold trap filled with liquid nitrogen. Both solid and aqueous phases were also retained for further separation by ion exchange chromatography, as described below.

Reduction of $U(V)-d p a e a$. As $U(V)$ is highly sensitive to oxidation, all materials were left at least $24 \mathrm{~h}$ under vacuum prior to entering the anoxic chamber, and allowed to equilibrate for 2-3 days under anoxic conditions before use. Regarding the preparation of the cells, in addition to the three washes in modified anoxic WLP, 10 min cycles of vacuum followed by nitrogen injection were done (in the headspace of a $10 \mathrm{~mL}$ anaerobic glass vial). Two sets of experiments were performed. The first set (called "biological"), used as a starting material $U(V)$-dpaea biologically produced via reduction of U(VI)-dpaea with S. oneidensis MR-1 (described above). The supernatant of the culture incubated with $U(V I)-$ dpaea was recovered by filtration through $0.2 \mu \mathrm{m}$ filters. As U(VI)-dpaea is insoluble, the majority of $U$ in solution was expected (and later confirmed) to be $U(V)$-dpaea. The second set (called "synthetic") used synthetic U(V)-dpaea prepared as previously described $\left(\left([\mathrm{K}(2.2 .2\right.\right.$.cryptand $)]\left[\mathrm{UO}_{2}\right.$ (dpaea) $\left.)\right] \mathrm{MW}=$ $\left.998.93 \mathrm{~g} \cdot \mathrm{mol}^{-1}\right) .^{38}$ For both starting materials, S. oneidensis MR-1 was incubated with soluble U(V)-dpaea and $20 \mathrm{mM}$ lactate. The initial concentration of $U$ in the "biological" set was $50 \mu \mathrm{M}$ (corresponding to about $100 \mu \mathrm{g}$ of $\mathrm{U}(\mathrm{V})-$ dpaea) and in the "synthetic" set, $30 \mu \mathrm{M}$ (corresponding to $60 \mu \mathrm{g}$ of $\mathrm{U}(\mathrm{V})$-dpaea). Both types of systems were incubated for 13 days in the glovebox, in the dark.

All experiments were conducted in duplicate and a no-cell control experiment was performed in parallel. The no-cell control experiment consisted of $\mathrm{U}(\mathrm{V})$-dpaea, either "biological" or "synthetic", in modified WLP anoxic medium (identical to the one used for the cells) in the presence of 20 $\mathrm{mM}$ lactate. At specific times, entire cultures were sacrificed 
from each "biological" and "synthetic" $\mathrm{U}(\mathrm{V})$-dpaea incubations, and associated no-cell or inactive cell controls (where relevant), followed by separation of $\mathrm{U}(\mathrm{VI})$ and $\mathrm{U}(\mathrm{IV})$ by ion exchange chromatography. Confirmatory UV-vis characterization was performed in selected cases (SI Text S2 and Figure S1).

Additionally, experiments were conducted with a control consisting of a deletion mutant lacking one gene from the maturation system of the $c$-type cytochrome pool, $\Delta c c m G$ (SI Text S3 and Text S4, Figure S2, Tables S2 and S3).

In order to analyze the end-product of reduction by $\mathrm{U} \mathrm{M}_{4}$ edge HR-XANES spectroscopy, solid phase $U$ was recovered by centrifugation after 4 days of incubation of $S$. oneidensis MR1 with $400 \mu \mathrm{M}$ biologically produced $\mathrm{U}(\mathrm{V})$-dpaea and stored frozen until analysis.

Ion Exchange Chromatography. Ion exchange chromatography was performed to resolve the $U$ oxidation state in both the solid and aqueous phases as a function of time, for both the $\mathrm{U}(\mathrm{VI})$ and $\mathrm{U}(\mathrm{V})$ reduction experiments described in the previous sections. Separation was achieved with Dowex $1 \times$ 8 powder (100-200 mesh; chloride form) packed in polypropylene chromatography columns (Poly-Prep, Bio-Rad, Hercules, California, United-States) inside the anaerobic chamber. The Dowex resin is a strongly basic cationic resin which allows the separation of $\mathrm{U}(\mathrm{VI})$ from $\mathrm{U}(\mathrm{IV})$ in an $\mathrm{HCl}$ acidified sample. ${ }^{39,40}$ For U(VI) reduction experiments, aqueous phases (supernatants) were collected and diluted in anoxic $\mathrm{HCl}$ to a final concentration of $4.5 \mathrm{M} \mathrm{HCl}$, and solid phases (cell pellets) were digested in $4.5 \mathrm{M} \mathrm{HCl}$. After digestion, samples were loaded onto resin slurry-packed columns that were pretreated with $4.5 \mathrm{M} \mathrm{HCl}$. The U(IV) fraction was eluted first in about $30 \mathrm{~mL}$ of anoxic $4.5 \mathrm{M} \mathrm{HCl}$ ( 15 bed volumes), followed by elution of the U(VI) fraction in $0.1 \mathrm{M} \mathrm{HCl}$, again in approximately 15 bed volumes of eluent. All separations were performed in analytical grade $\mathrm{HCl}$.

Uranium Quantification. Details of the uranium quantification by ICP-MS are described in the Supporting Information (Text S5).

HR-XANES. $\mathrm{U} \mathrm{M}_{4}$-edge (3.726 keV) HR-XANES was used to elucidate the oxidation state of $U$ in selected samples. Spectra were collected at the station for actinide science (ACT) at the CAT-ACT beamline at the Karlsruhe Research Accelerator (KARA), Karlsruhe, Germany. The CAT-ACT beamline is equipped with a Johann type X-ray emission spectrometer. ${ }^{41}$ The incident beam was monochromatized by a $\mathrm{Si}(111)$ double crystal monochromator (DCM) and focused onto the sample to a spot size of about $500 \mu \mathrm{m} \times 500 \mu \mathrm{m}$. The $\mathrm{X}$-ray emission spectrometer consists of four Si (110) crystals with $1 \mathrm{~m}$ bending radius and a single diode VITUS silicon drift detector (Ketek, Germany), which together with the sample are arranged in a vertical Rowland circle geometry. $\mathrm{A} \mathrm{UO}_{2}$ reference was used to calibrate the spectra. The main absorption maximum was set to $3.275 \mathrm{keV}$. The sample cells were placed in an inert gas cell and were constantly flushed with $\mathrm{He}$, maintaining anoxic conditions. The X-ray spectrometer was inside a He-flushed box in order to minimize intensity loss due to absorption or scattering of photons. Wet pastes and liquid samples were loaded into the sample holder in an anaerobic chamber, frozen immediately and stored on dry ice until the measurements. Regarding data processing, normalization and linear combination fits (LCF) were performed using the ATHENA software. ${ }^{42}$ The spectra obtained for the wet pastes and the liquids were modeled using the references
$\mathrm{U}(\mathrm{VI})$-dpaea, $\mathrm{U}(\mathrm{V})$-dpaea, and $\mathrm{U}(\mathrm{IV})$ - dpaea 2 , for which spectra were also collected and analyzed in the same manner. The goodness of fit was evaluated with two statistical parameters, the $\mathrm{R}$-factor and the reduced $\chi^{2}$, which were minimized by the fitting algorithm.

Electron Microscopy. We used scanning transmission electron microscopy (STEM), energy dispersive X-ray spectroscopy (EDS) and selected area electron diffraction (SAED) (FEI Tecnai Osiris, equipped with SuperX EDS detector) to characterize the product of $\mathrm{U}(\mathrm{V})$-dpaea reduction by $S$. oneidensis MR-1. Details of data collection and analysis are described in the Supporting Information (Text S6).

\section{RESULTS}

Reduction of $\mathrm{U}(\mathrm{VI})$-DPAEA. Transformation of $U(\mathrm{VI})-$ dpaea by S. oneidensis MR-1. U(VI) reduction by strain MR1 has been studied extensively. ${ }^{3,4,8,9,22}$ Here, in contrast to most previous studies, we considered the reduction of solid phase $U(V I)$, in the form of $U(V I)$-dpaea. In fact, we expected that the reduction of $\mathrm{U}(\mathrm{VI})$-dpaea would result in the formation of the soluble $U(V)$-dpaea complex, ${ }^{38}$ effectively reductively mobilizing $\mathrm{U}$. Therefore, we monitored $\mathrm{U}$ concentration in the incubation supernatants through time by ICP-MS. As illustrated in Figure 1A, we observed an
A.

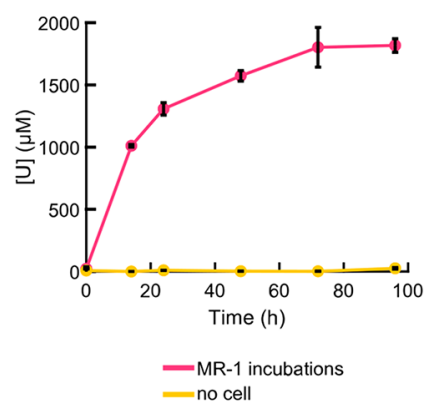

B.

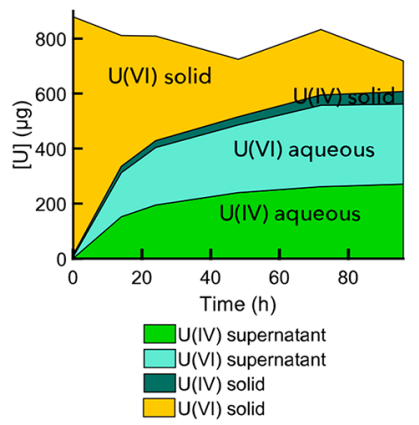

Figure 1. A. $U$ concentration in the incubation supernatants (pink dots) and in no-cell controls (yellow dots), measured from 0 to $96 \mathrm{~h}$ of incubation with $\mathrm{U}(\mathrm{VI})$-dpaea (in duplicates). B. U speciation in the solid phase and in the aqueous phase of the incubations (in $\mu \mathrm{g}$ ). The $\mathrm{U}(\mathrm{VI})$ and $\mathrm{U}(\mathrm{IV})$ fractions were obtained by ion exchange chromatography.

increase in the $U$ concentration in the culture supernatants, up to $1.9 \mathrm{mM}$ (corresponding to $75 \%$ of total $\mathrm{U}$ ) after $96 \mathrm{~h}$ of incubation. The no-cell control experiments showed a low $\mathrm{U}$ concentration in solution $(50 \mu \mathrm{M}$, corresponding to $2 \%$ of total $U$ in this experiment) due to the low solubility of the U(VI)-dpaea complex (SI Figure S3). Thus, we propose that solid phase $\mathrm{U}(\mathrm{VI})$-dpaea was being transformed by $S$. oneidensis MR-1, forming soluble $U$ species. In addition, we noticed that the aqueous phase turned pink. Therefore, we attempted to follow the reaction by UV-vis spectroscopy (SI Figure S1A). UV-vis spectra of the aqueous phase were collected at $0 \mathrm{~h}, 24 \mathrm{~h}$, and $72 \mathrm{~h}$. At $0 \mathrm{~h}$, we did not detect any light-absorbing compound. However, after $24 \mathrm{~h}$ and $72 \mathrm{~h}$, light absorbance was detected and the spectra showed a broad line with a maximum at $460 \mathrm{~nm}$. By comparing this spectrum with the reference spectra of $U(V)$-dpaea under identical conditions, we hypothesized that $\mathrm{U}(\mathrm{V})$-dpaea was formed in the aqueous phase of the incubations. 
Ion Exchange Chromatography of $U(V I)$ and $U(I V)$. In order to further confirm our hypothesis that the soluble $U$ product that accumulated in the aqueous phase was pentavalent $\mathrm{U}$, we performed ion exchange chromatography. For each time point, we were able to delineate the contribution of U(VI) and U(IV) as shown in Figure 1B and SI Table S4. As the amount of solid phase U(VI)-dpaea decreased, we observed the formation of a small amount of solid phase $\mathrm{U}(\mathrm{IV})$, and increasing $\mathrm{U}(\mathrm{VI})$ and $\mathrm{U}(\mathrm{IV})$ in the aqueous phase. The ion exchange chromatography separation cannot directly identify $U(V)$, because the samples are acidified prior to loading onto the column. Acid treatment is known to disproportionate uranyl $(\mathrm{V})$ and to produce equal proportions of $\mathrm{U}(\mathrm{VI})$ and $\mathrm{U}(\mathrm{IV}) .{ }^{24} \mathrm{We}$ observed that, at all incubation times analyzed, aqueous U(VI), and U(IV) were distributed in the supernatants at a contribution of $55 \%$ and $45 \%$, respectively, suggesting that $\mathrm{U}(\mathrm{V})$-dpaea formed and accumulated in the supernatant. The slight excess of aqueous $\mathrm{U}(\mathrm{VI})$ (corresponding to $50 \mu \mathrm{M} \mathrm{U}$ ) was attributed to the solubility (albeit low) of U(VI)-dpaea (SI Figure S3).

To confirm that the obtained ratio of $U(V I)$ and $U(I V)$ is a proxy for $\mathrm{U}(\mathrm{V})$-dpaea, we eluted a preparation of $600 \mu \mathrm{M}$ synthetic $U(V)$-dpaea under similar conditions. After acidification and separation, $U$ concentrations in the $U(V I)$ and $\mathrm{U}(\mathrm{IV})$ fractions were $294.6 \mu \mathrm{M}$ and $294.4 \mu \mathrm{M}$, respectively. This test confirmed that a $1: 1 \mathrm{U}(\mathrm{VI}) / \mathrm{U}(\mathrm{IV})$ ratio obtained after ion exchange chromatography separation, corresponds to $\mathrm{U}(\mathrm{V})$.

$M_{4}$-Edge HR-XANES. To provide further evidence for the oxidation state of $U$ in the aqueous and solid phases, we collected $\mathrm{M}_{4}$-edge HR-XANES spectra. Late time points were selected in order to ensure that a sufficiently high concentration of $U$ had accumulated in the aqueous phase to allow the acquisition of spectra with a high signal-to-noise ratio (Figure 2). The energy positions of the first intense absorption

A.

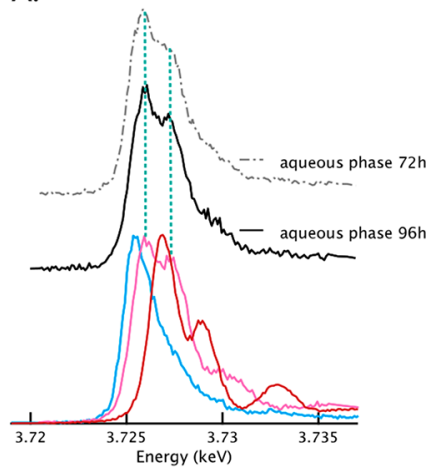

B.

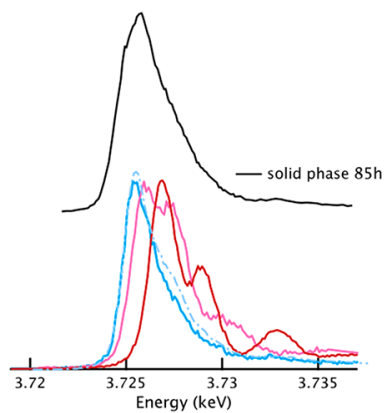

-U(IV)-dpaea

-U(V)-dpaea

$-\cdot-\mathrm{UO}_{2}$

Figure 2. $\mathrm{U} \mathrm{M}_{4}$-edge HR-XANES spectra demonstrating reduction of (A) $\mathrm{U}(\mathrm{VI})$-dpaea and (B) biologically produced $\mathrm{U}(\mathrm{V})$-dpaea. The references $\mathrm{U}(\mathrm{VI})$-dpaea (in red), $\mathrm{U}(\mathrm{V})$-dpaea (in pink) and $\mathrm{U}(\mathrm{IV})-$ dpaea $_{2}$ (in blue) are presented in both panels. The spectra obtained for $\mathrm{UO}_{2}$ is shown as a dashed line. $\mathrm{U}(\mathrm{IV})-$ dpaea $_{2}$ was used as a reference and likely does not fully characterize the U(IV) phases present. In addition to the references, the spectra obtained for (A) the aqueous phase after $72 \mathrm{~h}$ and $96 \mathrm{~h}$ of incubation, and for (B) the solid phase (cell pellet) collected after $85 \mathrm{~h}$ of incubation of $S$. oneidensis MR-1 with $U(V)-$ dpaea are presented. peak of the spectra of the $U(I V)$-dpaea, $U(V)$-dpaea and $\mathrm{U}(\mathrm{VI})$-dpaea references shift to higher energies in the order $\mathrm{U}(\mathrm{IV}), \mathrm{U}(\mathrm{V}), \mathrm{U}(\mathrm{VI})$ (Figure $2 \mathrm{~A})$. The energy positions of the spectral features are listed in SI Table S5. The spectra of $\mathrm{U}(\mathrm{VI})$-dpaea and $\mathrm{U}(\mathrm{V})$-dpaea displayed shapes typical for uranyl(VI) $\left(\mathrm{UO}_{2}{ }^{2+}\right)$ and $\operatorname{uranyl}(\mathrm{V})$, respectively. ${ }^{43,44}$ The spectra obtained for the supernatants (aqueous phase) collected after $72 \mathrm{~h}$ and $96 \mathrm{~h}$ of incubation (Figure 2A.) resembled closely that of $\mathrm{U}(\mathrm{V})$-dpaea, which confirms the ion exchange chromatography results (Figure 1). The spectra of the samples feature two intense peaks with maxima at 3.7258 and $3.7272 \mathrm{keV}$ for the $72 \mathrm{~h}$ sample and at 3.7260 and 3.7272 $\mathrm{keV}$ for the $96 \mathrm{~h}$ sample. In comparison, the U(V)-dpaea standard exhibits peak maxima of those peaks at 3.7258 and $3.7271 \mathrm{keV}$ (SI Table S5). Moreover, linear combination fits (LCF) (SI Figures S4 and S5) revealed that both supernatants contained more than $80 \% \mathrm{U}(\mathrm{V})$, as reported in SI Table S6. Furthermore, the split peak at $3.7258-3.7260$ to $3.7272 \mathrm{keV}$ in both the uranyl(V) standard and the samples (SI Figure S4) indicated the presence of $\operatorname{uranyl}(\mathrm{V})$ rather than uranate(V). ${ }^{16,43}$ Qualitative analysis of $\mathrm{M}_{4}$-edge HR-XANES data show that the $\mathrm{U}$ solid phase collected after $150 \mathrm{~h}$ (SI Figure S6) is mainly composed of $\mathrm{U}(\mathrm{VI})$-dpaea with small contributions of U(IV) and possibly U(V) (SI Table S6). We interpret this result as the contribution of residual solid phase $\mathrm{U}(\mathrm{VI})$ combined with a small amount of precipitated $\mathrm{U}(\mathrm{IV})$. We attribute the presence of $\mathrm{U}(\mathrm{V})$ in the solid phase to the sorption of soluble $\mathrm{U}(\mathrm{V})$-dpaea on the cells or the surface of $\mathrm{U}(\mathrm{VI})$--dpaea.

Reduction of $\mathrm{U}(\mathrm{V})-\mathrm{dpaea}$. In order to probe whether biological reduction of $\mathrm{U}(\mathrm{V})$-dpaea occurred in these experiments, we performed two additional bio-reduction experiments with $\mathrm{U}(\mathrm{V})$-dpaea as the starting substrate. The first, utilizing biologically generated $U(V)$-dpaea, was performed to establish the continuity of the reduction mechanism from $U(V I)$ to $U(I V)$. The second, utilizing chemically synthesized $\mathrm{U}(\mathrm{V})$-dpaea, was performed in order to systematically uncouple the second electron transfer $(\mathrm{U}(\mathrm{V})$ to $\mathrm{U}(\mathrm{IV})$ ) from the first (U(VI) to $\mathrm{U}(\mathrm{V})$ ).

For this set of experiments, we validated the ion-exchange chromatography by testing it on decreasing $\mathrm{U}(\mathrm{V})$-dpaea concentrations (from $220 \mu \mathrm{M}$ to $4.2 \mu \mathrm{M}$ ). We noticed that the $\mathrm{U}(\mathrm{VI}) / \mathrm{U}(\mathrm{IV})$ ratio obtained after separation of $\mathrm{U}(\mathrm{V})$-dpaea was dependent on the initial $\mathrm{U}(\mathrm{V})$-dpaea concentration in solution, before acid treatment (SI Figure S7). Therefore, the results of the $U(V)$-dpaea reduction experiments, presented in the sections below, were corrected after establishing the relationship between initial $[\mathrm{U}(\mathrm{V})-$ dpaea $]$ and the percentage of $U$ in the $U(I V)$ fraction (SI Figure S8). We also evaluated that the dpaea ligand does not have an effect on chromatography elution (SI Figure S9). The details of this correction factor are reported in the Supporting Information (Text S7).

Reduction of Biologically Produced U(V)-dpaea. Aqueous $U$ concentrations were monitored in incubations of $S$. oneidensis with biogenic $\mathrm{U}(\mathrm{V})$-dpaea over up to $312 \mathrm{~h}$ (13 days). Over this experimental time, we showed that the cell number decreased but remained greater than a thousand cells/ $\mathrm{mL}$ (experimental method described in SI Text S2, and results in SI Figure S10). While the concentration of aqueous $U$ remained constant at around $50 \mu \mathrm{M}$ in the controls without cells over the duration of the experiment, aqueous $U$ in the biological incubations decreased steadily down to $30 \mu \mathrm{M}$ 
(Figure 3A). In addition, as $\mathrm{U}(\mathrm{V})$-dpaea was removed from the aqueous phase, a concomitant increase in solid-associated

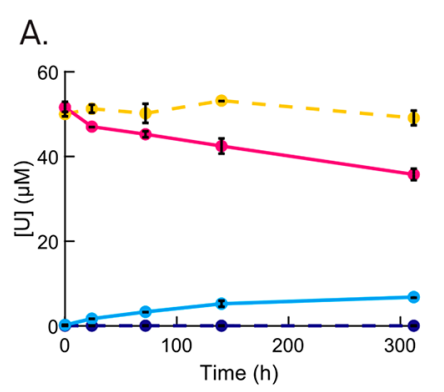

B.

$$
\begin{aligned}
& \text { - - no cell - aqueous phase }- \text { MR-1 - aqueous phase } \\
& \text { - - no cell - solid phase } \quad \text { MR-1 - solid phase }
\end{aligned}
$$

Figure 3. Aqueous and solid phase $U$ concentration through time in incubations with $S$. oneidensis MR-1 and no-cell controls with (A) biologically produced $\mathrm{U}(\mathrm{V})$-dpaea $(\mathrm{B})$ synthetic $\mathrm{U}(\mathrm{V})$-dpaea.

$\mathrm{U}$ was observed (Figure 3A). In contrast, we did not observe the formation of a solid phase in the abiotic controls. Ion exchange chromatography of the solid phases recovered from the incubations revealed that they are composed of U(IV) (Figure 4A). We further substantiate $\mathrm{U}$ speciation in the solid

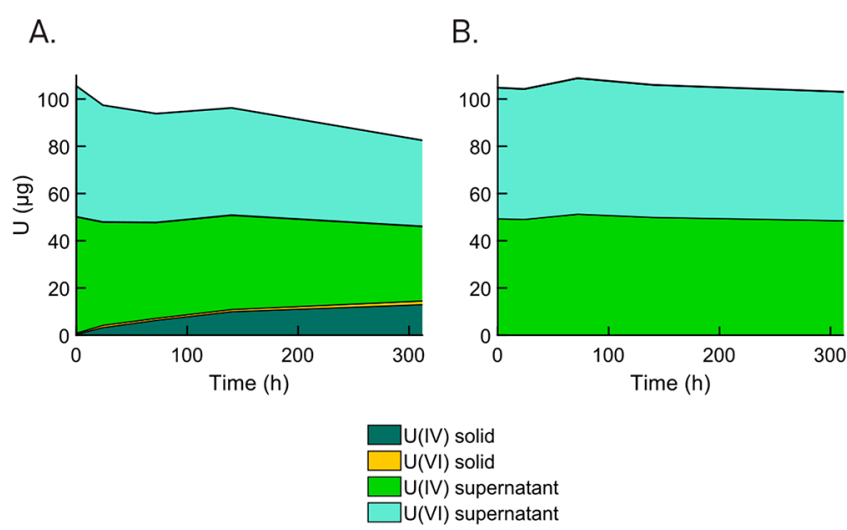

Figure 4. $U$ oxidation state in the solid phase (cell pellet) and in the aqueous phase (supernatant) of (A) incubations with $S$. oneidensis MR-1 (B) and no-cell controls, in the presence of "biological" U(V)dpaea. The $\mathrm{U}(\mathrm{VI})$ and $\mathrm{U}(\mathrm{IV})$ fractions were obtained by ion exchange chromatography. The ion exchange chromatography separation cannot directly identify $\mathrm{U}(\mathrm{V})$, because the samples are acidified prior to loading onto the column. Acid treatment is known to disproportionate uranyl $(\mathrm{V})$ and to produce equal proportions of $\mathrm{U}(\mathrm{VI})$ and $\mathrm{U}(\mathrm{IV})$. Therefore, here the equal proportions observed for $\mathrm{U}(\mathrm{VI})$ and $\mathrm{U}(\mathrm{IV})$ in the supernatant are a proxy for $\mathrm{U}(\mathrm{V})$ (result demonstrated by $\mathrm{U} \mathrm{M}_{4}$-edge HR-XANES).

phase using $\mathrm{M}_{4}$-edge HR-XANES (Figure 2B). The spectra collected for the solid phase $U$ recovered after $85 \mathrm{~h}$ of incubation showed a single peak at $3.7257 \mathrm{keV}$ (SI Table S5), similar to the U(IV)- dpaea ${ }_{2}$ standard, and LCF suggests a composition of $\sim 90 \% \mathrm{U}(\mathrm{IV})$ with a small contribution of $\mathrm{U}(\mathrm{V})$, most likely in an uranate configuration (SI Table S6).

To better delineate the nature of the U(IV) product, samples of the cell pellet recovered after 3 months of incubation were analyzed by TEM. We pinpointed two major morphologies of the U(IV) product which are represented in Figure 5. The first morphology corresponds to aggregates of $\mathrm{U}$, smaller than $200 \mathrm{~nm}$, distributed at the surface of the bacteria (Figure $5 \mathrm{~A}-\mathrm{C}$ ), and the second exhibits U-bearing clusters larger than $1 \mu \mathrm{m}$ associated with biomass (Figure 5D-F). EDS spectra of the two types of $U$ morphology showed the predominance of $\mathrm{U}$ and $\mathrm{O}$ for both types but only significant contributions of $\mathrm{N}$ for type 2 (SI Figure S11). SAED diffraction patterns also acquired on both morphologies display diffuse rings, suggesting that both are noncrystalline (SI Figures S12 and S13). We propose that the type 2 morphology may correspond to U(IV)-dpaea ${ }_{2}$ (a sparingly soluble complex with an equilibrium solubility of 10 $\mu \mathrm{M}$, SI Figure S3) and type 1 to non-crystalline U(IV) typically expected in U(VI) reduction by bacteria ${ }^{4}$ EXAFS analysis is needed to determine definitively the structure of the end product.

Reduction of Synthetic U(V)-dpaea. We observed similar results when the same experiment was conducted with synthetic $\mathrm{U}(\mathrm{V})$-dpaea. Indeed, $\mathrm{U}$ remained stable in the nocell controls at around $27 \mu \mathrm{M}$ (Figure 3B). In contrast, the amount of $U$ in solution decreased steadily in the culture supernatants down to $13 \mu \mathrm{M}$, with the concomitant formation of a solid phase (Figure 3B). Ion exchange chromatography separation of the acid-solubilized solid phase also showed the predominance of solid U(IV) (SI Figure S14). Furthermore, UV-vis spectroscopy of the aqueous phase showed (i) stability of $\mathrm{U}(\mathrm{V})$-dpaea in the aqueous phase in the absence of cells and (ii) a slight decrease in the absorbance for incubations with cells further supporting that $\mathrm{U}(\mathrm{V})$-dpaea was transformed by the bacteria (SI Figure S3B). Cell viability was monitored over 30 days (SI Figure S10), and shown to decrease, as expected, but to remain above $10^{3}$ cells $/ \mathrm{mL}$.

Reduction Is the Dominant Mechanism. In order to confirm that the solid phase U(IV) observed in the incubations of $S$. oneidensis MR-1 with $\mathrm{U}(\mathrm{V})$-dpaea was the product of an active reduction mechanism, we probed the ability of a $\mathrm{ccm} G$ deletion mutant to carry out the reduction. The $\Delta c c m G$ mutant lacks a key gene involved in the maturation of $c$-type cytochromes, and therefore is devoid of these proteins. Hence, in an experiment similar to the one described above, we incubated $\Delta c c m G$ cells, MR-1 wild type (WT) cells, and a nocell control with $550 \mu \mathrm{M}$ synthetic $\mathrm{U}(\mathrm{V})$-dpaea. As expected, $\Delta c c m G$ cells did not transform $\mathrm{U}(\mathrm{V})$-dpaea over $336 \mathrm{~h}$ (14 days) (Figure 6A), whereas we observed a $20 \%$ decrease in the concentration of $\mathrm{U}(\mathrm{V})$-dpaea in the incubations with MR-1 WT cells and a $2.5 \%$ decrease for the no-cell control. This finding suggests that the presence of $c$-type cytochromes is required for $\mathrm{U}(\mathrm{V})$-dpaea reduction. Additionally, we can exclude disproportionation as a significant contributor to $\mathrm{U}(\mathrm{V})$-dpaea reduction. This is because $\mathrm{U}(\mathrm{V})$-dpaea reduction does not occur in the presence of the $\Delta c c m G$ mutant. Furthermore, the complex is stable in the absence of cells (no-cell control), or in the presence of inactivated cells (SI Text S8 and S9, Figures S15, S16, and S17). In contrast, we observed the substantial decrease in the concentration of $\mathrm{U}(\mathrm{V})$-dpaea in the presence of active WT cells, providing evidence for microbial $\mathrm{U}(\mathrm{V})$-dpaea reduction. These results concur to demonstrate that $\mathrm{U}(\mathrm{V})$-dpaea can be actively reduced by strain MR-1 cells via an electron transfer flow likely mediated by $c$-type cytochromes.

Mechanism of $\mathrm{U}(\mathrm{VI})-$ dpaea Reduction. We report that S. oneidensis MR-1 can reduce solid phase U(VI)-dpaea to uranyl $(\mathrm{V})$-dpaea by a one-electron transfer. $\mathrm{U}(\mathrm{V})$-dpaea is released in the culture supernatant and remains stable over the duration of the experiment. The use of the dpaea ligand to 


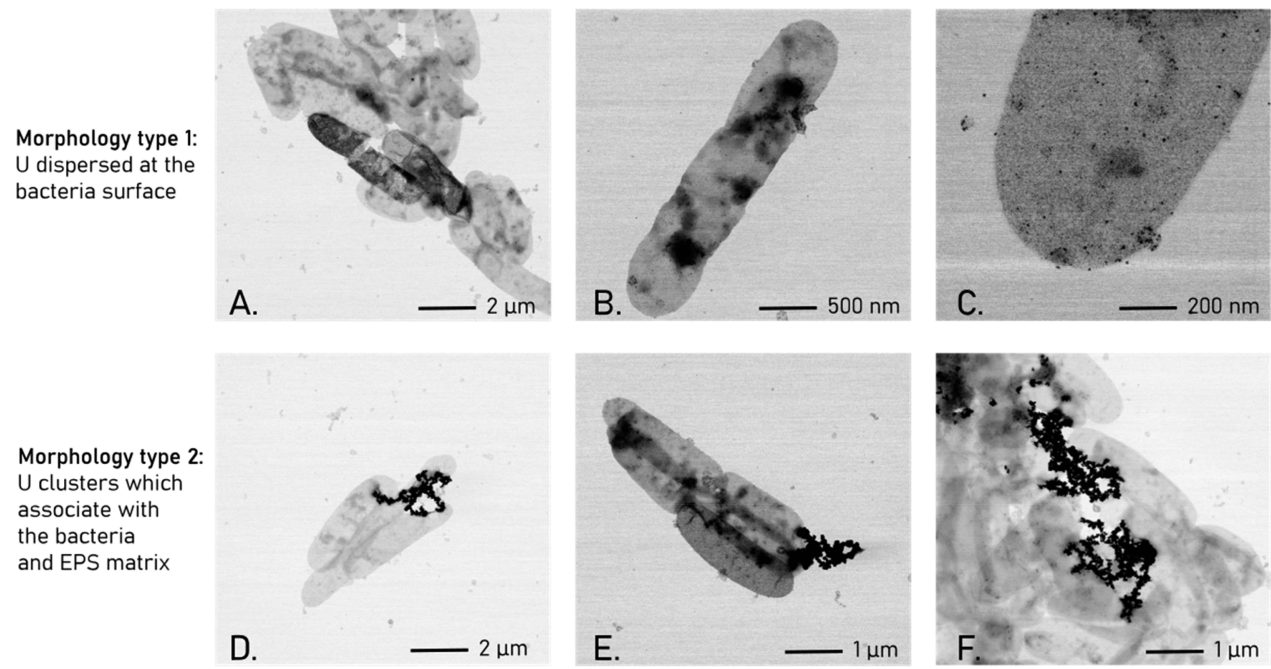

Figure 5. STEM images acquired on S. oneidensis MR-1 incubated with U(V)-dpaea for 3 months. We mainly observed two types of uranium morphologies. A, B, and C describe morphology type 1 corresponding to $\mathrm{U}$ aggregates smaller than $200 \mathrm{~nm}$ dispersed at the surface of the bacteria. $\mathrm{D}, \mathrm{E}$, and $\mathrm{F}$ show morphology type 2 , in which $\mathrm{U}$ forms larger $(>1 \mu \mathrm{m}$ or $\mu \mathrm{m})$ clusters in association with the bacterial cells.
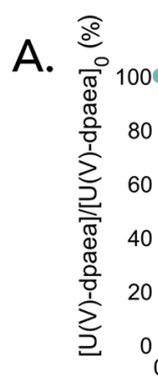

B.

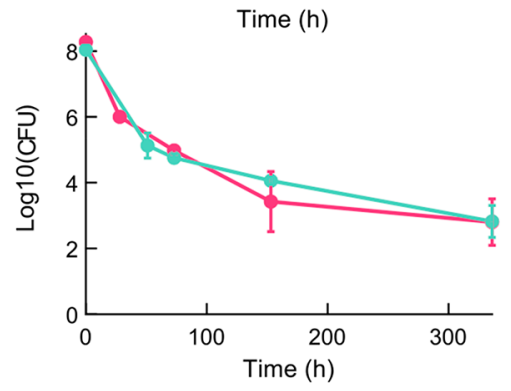

Figure 6. Aqueous $U(V)-$ dpaea concentration (A) and cell viability (B) through time in incubations with $S$. oneidensis MR-1, the deletion mutant $\Delta c c m G$ and a no-cell control.

coordinate and stabilize $\mathrm{U}(\mathrm{V})$ in water at $\mathrm{pH} 7$ allowed for the accumulation of this intermediate in solution. Our results are congruent with the Renshaw et al. and others, ${ }^{18,21,22}$ where a transient uranyl(V) species was proposed to form in Geobacter sulfurreducens cell suspensions after $4 \mathrm{~h}$ of incubation. However, additionally, our system evidenced the biological reduction of $\mathrm{U}(\mathrm{V})$-dpaea by an additional one-electron transfer. Clearly, the enhanced stability of $U(V)$ afforded by the dpaea ligand extends the half-life of $U(V)$ in solution, allowing this process to take place. The significance of the results lies in the demonstration that $S$. oneidensis MR-1 cells are able to actively reduce $\mathrm{U}(\mathrm{V})$-dpaea. This finding is consistent with the reduction of $\mathrm{Np}(\mathrm{V})$ and $\mathrm{Pu}(\mathrm{V})$ by the same organism. ${ }^{27,28}$ It is conceivable that the same would occur for $\mathrm{U}(\mathrm{V})$ organic complexes provided that they persist sufficiently long for biological reduction to preempt disproportionation.
Thus, the molecular mechanism of $\mathrm{U}(\mathrm{VI})$-dpaea reduction is distinct from that described by Sundararajan et al. for $\left[\mathrm{U}(\mathrm{VI}) \mathrm{O}_{2}\left(\mathrm{H}_{2} \mathrm{O}\right)_{5}\right]^{2+}$. ${ }^{4}$ They assumed that a transient $\mathrm{U}(\mathrm{V})$ species formed after the transfer of two electrons from the $c$ type cytochrome PpcA of Geobacter sulfurreducens to the associated $\mathrm{U}(\mathrm{VI})-\mathrm{U}(\mathrm{VI})$ dimer. In the proposed scenario, a $\mathrm{U}(\mathrm{V})-\mathrm{U}(\mathrm{V})$ dimer is formed and disproportionates to $\mathrm{U}(\mathrm{VI})$ and $U(I V)$. In this work, it is unlikely that such a dimer can form because of the bulky pentadentate ligand dpaea. In fact, the dpaea ligand obstructs the equatorial plane of the $U$ atom, preventing CCI and thus, disproportionation. Therefore, we suggest that electron transfer involved a monomer U(VI)dpaea. Once $U(V)$-dpaea was formed in the supernatant, it remained stable until further reduction occurred. Spontaneous disproportionation was excluded since the structure was found to be stable up to three months in water at $\mathrm{pH} 7 .^{38}$ Moreover, $[\mathrm{U}(\mathrm{V})$-dpaea] remained unchanged in the no-cell and $\Delta c \mathrm{~cm} G$ mutant controls over the course of our assays.

The reduction of water stable $U(V)$-dpaea to $U(I V)$ implies that structural changes took place, namely the cleavage of the two uranyl dioxo bonds. The process may be facilitated by the functionalization of one of the uranyl oxygen atoms ${ }^{46}$ by hydrogen binding with an enzymatic residue of the outermembrane cytochromes MtrC or OmcA. Also, the second reduction step exhibited slower kinetics than the first, with half-lives of $984 \mathrm{~h}$ (41 days) and $528 \mathrm{~h}$ (22 days) for the "biological" and "synthetic" U(V)-dpaea, respectively, compared to $20 \mathrm{~h}$ for $\mathrm{U}(\mathrm{VI})$-dpaea reduction to $\mathrm{U}(\mathrm{V})$-dpaea.

Thermodynamic Considerations. The MtrCAB protein complex in S. oneidensis MR-1 spans potentials from 0 to -400 $\mathrm{mV}$ (against the standard hydrogen electrode (SHE)), ${ }^{47}$ and therefore accesses a large range of redox substrates. The reduction potential of $\mathrm{U}(\mathrm{VI})$-dpaea/U(V) -dpaea was -312 $\mathrm{mV}$ (SHE), ${ }^{37}$ thus, the first reduction step of $\mathrm{U}(\mathrm{VI})$ to $\mathrm{U}(\mathrm{V})$, lies within the reduction potentials accessible to the MtrCAB complex. It suggests that a one-electron reduction of $\mathrm{U}(\mathrm{VI})-$ dpaea by MtrC/OmcA would be energetically favorable.

Regarding the second reduction step from $\mathrm{U}(\mathrm{V})$-dpaea to $\mathrm{U}(\mathrm{IV})$, there is no reported redox potential for the $\mathrm{U}(\mathrm{V})-$ $\mathrm{dpaea} / \mathrm{U}(\mathrm{IV})$ in aqueous medium. Indeed, the absence of a redox wave on the cyclic voltammogram of $U(V)$-dpaea 
associated with the transition of $\mathrm{U}(\mathrm{V})$ to $\mathrm{U}(\mathrm{IV})$ may be explained by the slow kinetics of electron transfer or by significant structural rearrangements. ${ }^{37}$ However, dithionite, which is the reduced product in the sulfite/dithionite couple $\left(\mathrm{HSO}_{3}{ }^{2-} / \mathrm{S}_{2} \mathrm{O}_{4}{ }^{2-}\right)$, with an electrochemical potential of -660 $\mathrm{mV}$ against $\mathrm{SHE}$ at $\mathrm{pH} 7$, was shown experimentally to reduce $\mathrm{U}(\mathrm{V})$-dpaea to $\mathrm{U}(\mathrm{IV})$ in an aqueous solution buffered at $\mathrm{pH}$ 7 with HEPES. ${ }^{37}$ This observation implies that the redox potential of $\mathrm{U}(\mathrm{V})$-dpaea/U(IV) could be accessible by MtrC/ OmcA and a one-electron reduction of $\mathrm{U}(\mathrm{V})$-dpaea to $\mathrm{U}(\mathrm{IV})$, energetically favorable.

Environmental Relevance. In this work, the dpaea ligand was a powerful tool to characterize the reduction mechanism of $\mathrm{U}$ reduction and to trap the pentavalent species. This is an approach that allowed the elucidation of whether biological $\mathrm{U}(\mathrm{V})$ reduction was possible in the presence of organic ligands closely related to dipicolinic acid. With this point now resolved, it opens the door for investigations with more environmentally relevant ligands.

Bulky ligands and ligands that can bind metal ions with a high number of donor atoms may contribute to slowing down the disproportionation, by preventing CCI between two uranium nuclei. The dpaea ligand displays significant steric effects around the $U$ nucleus because of the aromatic rings occupying the equatorial plane of the complex. In addition, this ligand is pentadentate and therefore occupies five coordination sites at the metal center, which prevents disproportionation. ${ }^{48,49}$ In contrast, smaller ligands or ligands with a coordination number lower than 3 may allow CCI and consequently disproportionation. ${ }^{50}$

We expect that other polydentate ligands, with similar properties as dpaea, may stabilize uranyl $(\mathrm{V})$ sufficiently to allow the reduction of the $\mathrm{U}(\mathrm{V})$ species. For instance, we could envision other aminocarboxylate ligands such as EDTA, NTA, or DTPA (used to extract radionuclides in the process of radioactive waste treatment ${ }^{33}$ ) may behave similarly. In addition, fulvic and humic acids, abundant in organic rich soils, have numerous carboxylic and hydroxyl functional groups and are additional candidates to stabilize $\operatorname{uranyl}(\mathrm{V})$ in the subsurface.

Additional work, with the above-mentioned ligands and in natural sediments, is needed to investigate these hypotheses. Moreover, the dpaea system could be a valuable system to interrogate the isotopic signature associated with a single oneelectron transfer step and how it impacts the overall isotopic fractionation of biological $U$ reduction.

\section{ASSOCIATED CONTENT}

\section{SI Supporting Information}

The Supporting Information is available free of charge at https://pubs.acs.org/doi/10.1021/acs.est.0c06633.

Methods, Supplementary tables, and figures (PDF)

\section{AUTHOR INFORMATION}

\section{Corresponding Author}

Rizlan Bernier-Latmani - Environmental Microbiology Laboratory, Ecole Polytechnique Fédérale de Lausanne (EPFL), Lausanne 1015, Switzerland; 이이.org/00000001-6547-722X; Email: rizlan.bernier-latmani@epfl.ch

\section{Authors}

Margaux Molinas - Environmental Microbiology Laboratory, Ecole Polytechnique Fédérale de Lausanne (EPFL), Lausanne 1015, Switzerland; (1) orcid.org/0000-0002-8795-0425

Radmila Faizova - Group of Coordination Chemistry, Ecole Polytechnique Fédérale de Lausanne (EPFL), Lausanne 1015, Switzerland

Ashley Brown - Environmental Microbiology Laboratory, Ecole Polytechnique Fédérale de Lausanne (EPFL), Lausanne 1015, Switzerland

Jurij Galanzew - Karlsruhe Institute of Technology (KIT), Institute for Nuclear Waste Disposal (INE), D-76021 Karlsruhe, Germany

Bianca Schacherl - Karlsruhe Institute of Technology (KIT), Institute for Nuclear Waste Disposal (INE), D-76021 Karlsruhe, Germany

Barbora Bartova - Environmental Microbiology Laboratory, Ecole Polytechnique Fédérale de Lausanne (EPFL), Lausanne 1015, Switzerland

Karin L. Meibom - Environmental Microbiology Laboratory, Ecole Polytechnique Fédérale de Lausanne (EPFL), Lausanne 1015, Switzerland

Tonya Vitova - Karlsruhe Institute of Technology (KIT), Institute for Nuclear Waste Disposal (INE), D-76021 Karlsruhe, Germany; 이이.org/0000-0002-3117-7701

Marinella Mazzanti - Group of Coordination Chemistry, Ecole Polytechnique Fédérale de Lausanne (EPFL), Lausanne 1015, Switzerland; 이이.org/0000-0002-3427-008X

Complete contact information is available at: https://pubs.acs.org/10.1021/acs.est.0c06633

\section{Author Contributions}

The manuscript was written through contributions from all authors. R.B.L. and M.Ma. conceived of the research. M.Mo. performed all the experiments with support from R.F. who synthesized the U-dpaea complexes, A.B., who developed the ion-exchange chromatography method, B.B., who performed the STEM analysis, and T.V., J.G., and B.S. who assisted with the HR-XANES measurements. All authors gave approval for the final version of the manuscript.

\section{Funding}

This research was supported financially by the Swiss National Science Foundation (SNSF) with project number is CR23I2_166455 and by the European Research Council Consolidator Grant 725675 (UNEARTH).

\section{Notes}

The authors declare no competing financial interest.

\section{ACKNOWLEDGMENTS}

We acknowledge the KIT light source for the infrastructure and we thank the Institute for Beam Physics and Technology (IBPT) for the operation of the storage ring, the Karlsruhe Research Accelerator (KARA). We acknowledge also Dr. Jörg Rothe and Dr. Kathy Dardenne for help with the organization of the synchrotron experiments and Dr. Kristina Kvashnina for fruitful discussions.

\section{REFERENCES}

(1) Ribera, D.; Labrot, F.; Tisnerat, G.; Narbonne, J. F. Uranium in the Environment: Occurrence, Transfer, and Biological Effects. Rev. Environ. Contam. Toxicol. 1996, 146, 53-89. 
(2) Markich, S. J. Uranium Speciation and Bioavailability in Aquatic Systems: An Overview. Sci. World J. 2002, 2, 707-729.

(3) Lovley, D. R.; Phillips, E. J. P.; Gorby, Y. A.; Landa, E. R. Microbial Reduction of Uranium. Nature 1991, 350 (6317), 413416.

(4) Bernier-Latmani, R.; Veeramani, H.; Vecchia, E. D.; Junier, P.; Lezama-Pacheco, J. S.; Suvorova, E. I.; Sharp, J. O.; Wigginton, N. S.; Bargar, J. R. Non-Uraninite Products of Microbial U(VI) Reduction. Environ. Sci. Technol. 2010, 44 (24), 9456-9462.

(5) Barton, L. L.; Choudhury, K.; Thomson, B. M.; Steenhoudt, K.; Groffman, A. R. Bacterial Reduction of Soluble Uranium: The First Step of in Situ Immobilization of Uranium. Radioact. Waste Manag. Environ. Restor. 1996, 20 (2-3), 141-151.

(6) Lovley, D. R.; Roden, E. E.; Phillips, E. J. P.; Woodward, J. C. Enzymatic Iron and Uranium Reduction by Sulfate-Reducing Bacteria. Mar. Geol. 1993, 113 (1-2), 13.

(7) Francis, A. J.; Dodge, C. J.; Lu, F.; Halada, G. P.; Clayton, C. R. XPS and XANES Studies of Uranium Reduction by Clostridium Sp. Environ. Sci. Technol. 1994, 28 (4), 636-639.

(8) Marshall, M. J.; Beliaev, A. S.; Dohnalkova, A. C.; Kennedy, D. W.; Shi, L.; Wang, Z.; Boyanov, M. I.; Lai, B.; Kemner, K. M.; McLean, J. S.; Reed, S. B.; Culley, D. E.; Bailey, V. L.; Simonson, C. J.; Saffarini, D. A.; Romine, M. F.; Zachara, J. M.; Fredrickson, J. K. CType Cytochrome-Dependent Formation of U(IV) Nanoparticles by Shewanella Oneidensis. PLoS Biol. 2006, 4 (8). .

(9) Bargar, J. R.; Bernier-Latmani, R.; Giammar, D. E.; Tebo, B. M. Biogenic Uraninite Nanoparticles and Their Importance for Uranium Remediation. Elements 2008, 4 (6), 407-412.

(10) Veeramani, H.; Alessi, D. S.; Suvorova, E. I.; Lezama-Pacheco, J. S.; Stubbs, J. E.; Sharp, J. O.; Dippon, U.; Kappler, A.; Bargar, J. R.; Bernier-Latmani, R. Products of Abiotic U(VI) Reduction by Biogenic Magnetite and Vivianite. Geochim. Cosmochim. Acta 2011, 75 (9), $2512-2528$.

(11) Veeramani, H.; Scheinost, A. C.; Monsegue, N.; Qafoku, N. P.; Kukkadapu, R.; Newville, M.; Lanzirotti, A.; Pruden, A.; Murayama, M.; Hochella, M. F. Abiotic Reductive Immobilization of U(VI) by Biogenic Mackinawite. Environ. Sci. Technol. 2013, 47 (5), 23612369.

(12) O’Loughlin, E. J.; Kelly, S. D.; Cook, R. E.; Csencsits, R.; Kemner, K. M. Reduction of Uranium(VI) by Mixed Iron(II)/ Iron(III) Hydroxide (Green Rust): Formation of UO2 Nanoparticles. Environ. Sci. Technol. 2003, 37 (4), 721-727.

(13) Scott, T. B.; Allen, G. C.; Heard, P. J.; Randell, M. G. Reduction of U(VI) to U(IV) on the Surface of Magnetite. Geochim. Cosmochim. Acta 2005, 69 (24), 5639-5646.

(14) Ilton, E. S.; Pacheco, J. S. L.; Bargar, J. R.; Shi, Z.; Liu, J.; Kovarik, L.; Engelhard, M. H.; Felmy, A. R. Reduction of U(VI) Incorporated in the Structure of Hematite. Environ. Sci. Technol. 2012, 46 (17), 9428-9436.

(15) Yuan, K.; Ilton, S. E.; Antonio, M. R.; Li, Z.; Cook, P. J.; Becker, U. Electrochemical and Spectroscopic Evidence on the OneElectron Reduction of $\mathrm{U}(\mathrm{VI})$ to $\mathrm{U}(\mathrm{V})$ on Magnetite. Environ. Sci. Technol. 2015, 49 (10). 62066213.

(16) Pidchenko, I.; Kvashnina, K. O.; Yokosawa, T.; Finck, N.; Bahl, S.; Schild, D.; Polly, R.; Bohnert, E.; Rossberg, A.; Göttlicher, J.; Dardenne, K.; Rothe, J.; Schäfer, T.; Geckeis, H.; Vitova, T. Uranium Redox Transformations after U(VI) Coprecipitation with Magnetite Nanoparticles. Environ. Sci. Technol. 2017, 51 (4), 2217-2225.

(17) Roberts, H. E.; Morris, K.; Law, G. T. W.; Mosselmans, J. F. W.; Bots, P.; Kvashnina, K.; Shaw, S. Uranium(V) Incorporation Mechanisms and Stability in $\mathrm{Fe}(\mathrm{II}) / \mathrm{Fe}(\mathrm{III})$ (Oxyhydr)Oxides. Environ. Sci. Technol. Lett. 2017, 4 (10), 421-426.

(18) Renshaw, J. C.; Butchins, L. J. C.; Livens, F. R.; May, I.; Charnock, J. M.; Lloyd, J. R. Bioreduction of Uranium: Environmental Implications of a Pentavalent Intermediate. Environ. Sci. Technol. 2005, 39 (15), 5657-5660.

(19) Gro $\beta$ mann, K.; Arnold, T.; Krawczyk-Bärsch, E.; Diessner, S.; Wobus, A.; Bernhard, G.; Krawietz, R. Identification of Fluorescent $\mathrm{U}(\mathrm{V})$ and $\mathrm{U}(\mathrm{VI})$ Microparticles in a Multispecies Biofilm by Confocal
Laser Scanning Microscopy and Fluorescence Spectroscopy. Environ. Sci. Technol. 2007, 41 (18), 6498-6504.

(20) Sundararajan, M.; Campbell, A. J.; Hillier, I. H. Catalytic Cycles for the Reduction of [UO2]2+ by Cytochrome C7 Proteins Proposed from DFT Calculations. J. Phys. Chem. A 2008, 112 (19), 4451-4457.

(21) Jones, D. L.; Andrews, M. B.; Swinburne, A. N.; Botchway, S. W.; Ward, A. D.; Lloyd, J. R.; Natrajan, L. S. Fluorescence Spectroscopy and Microscopy as Tools for Monitoring Redox Transformations of Uranium in Biological Systems. Chem. Sci. 2015, 6 (9), 5133-5138.

(22) Vettese, G. F.; Morris, K.; Natrajan, L. S.; Shaw, S.; Vitova, T.; Galanzew, J.; Jones, D. L.; Lloyd, J. R. Multiple Lines of Evidence Identify $\mathrm{U}(\mathrm{V})$ as a Key Intermediate during $\mathrm{U}(\mathrm{VI})$ Reduction by Shewanella Oneidensis MR1. Environ. Sci. Technol. 2020. 542268.

(23) Steele, H.; Taylor, R. J. A Theoretical Study of the Inner-Sphere Disproportionation Reaction Mechanism of the Pentavalent Actinyl Ions. Inorg. Chem. 2007, 46 (16), 6311-6318.

(24) Kern, D. M. H.; Orlemann, E. F. The Potential of the Uranium (V), Uranium (VI) Couple and the Kinetics of Uranium (V) Disproportionation in Perchlorate Media. J. Am. Chem. Soc. 1949, 71 (6), 2102-2106.

(25) Wang, Y.; Frutschi, M.; Suvorova, E.; Phrommavanh, V.; Descostes, M.; Osman, A. A. A.; Geipel, G.; Bernier-Latmani, R. Mobile Uranium(IV)-Bearing Colloids in a Mining-Impacted Wetland. Nat. Commun. 2013, 4, ncomms3942. DOI: 10.1038/ ncomms3942.

(26) Bhattacharyya, A.; Campbell, K. M.; Kelly, S. D.; Roebbert, Y.; Weyer, S.; Bernier-Latmani, R.; Borch, T. Biogenic Non-Crystalline U (IV) Revealed as Major Component in Uranium Ore Deposits. Nat. Commun. 2017, 8 (1), 15538.

(27) Icopini, G. A.; Boukhalfa, H.; Neu, M. P. Biological Reduction of $\mathrm{Np}(\mathrm{V})$ and $\mathrm{Np}(\mathrm{V})$ Citrate by Metal-Reducing Bacteria. Environ. Sci. Technol. 2007, 41 (8), 2764-2769.

(28) Icopini, G. A.; Lack, J. G.; Hersman, L. E.; Neu, M. P.; Boukhalfa, H. Plutonium(V/VI) Reduction by the Metal-Reducing Bacteria Geobacter Metallireducens GS-15 and Shewanella Oneidensis MR-1. Appl. Environ. Microbiol. 2009, 75 (11), 3641-3647.

(29) Nowack, B. Environmental Chemistry of Aminopolycarboxylate Chelating Agents. Environ. Sci. Technol. 2002, 36 (19), 4009-4016.

(30) Setlow, B.; Atluri, S.; Kitchel, R.; Koziol-Dube, K.; Setlow, P. Role of Dipicolinic Acid in Resistance and Stability of Spores of Bacillus Subtilis with or without DNA-Protective $\alpha / \beta$-Type Small Acid-Soluble Proteins. J. Bacteriol. 2006, 188 (11), 3740-3747.

(31) Takahashi, M.; Terada, Y.; Nakai, I.; Nakanishi, H.; Yoshimura, E.; Mori, S.; Nishizawa, N. K. Role of Nicotianamine in the Intracellular Delivery of Metals and Plant Reproductive Development. Plant Cell 2003, 15 (6), 1263-1280.

(32) Tandy, S.; Bossart, K.; Mueller, R.; Ritschel, J.; Hauser, L.; Schulin, R.; Nowack, B. Extraction of Heavy Metals from Soils Using Biodegradable Chelating Agents. Environ. Sci. Technol. 2004, 38 (3), 937-944.

(33) Nowack, B.; VanBriesen, J. M. Chelating Agents in the Environment. In Biogeochemistry of Chelating Agents; ACS Symposium Series; American Chemical Society, 2005; Vol. 910, pp 1-18. .

(34) Deblonde, G. J.-P.; Kelley, M. P.; Su, J.; Batista, E. R.; Yang, P.; Booth, C. H.; Abergel, R. J. Spectroscopic and Computational Characterization of Diethylenetriaminepentaacetic Acid/Transplutonium Chelates: Evidencing Heterogeneity in the Heavy Actinide(III) Series. Angew. Chem., Int. Ed. 2018, 57 (17). DOI: 10.1002/ anie.201709183.

(35) Brown, M. A.; Paulenova, A.; Gelis, A. V. Aqueous Complexation of Thorium(IV), Uranium(IV), Neptunium(IV), Plutonium(III/IV), and Cerium(III/IV) with DTPA. Inorg. Chem. 2012, 51 (14), 7741-7748.

(36) Lapka, J. L.; Paulenova, A.; Alyapyshev, M. Y.; Babain, V. A.; Herbst, R. S.; Law, J. D. Extraction of Uranium(VI) with Diamides of Dipicolinic Acid from Nitric Acid Solutions. Radiochim. Acta 2009, 97 (6), 291-296. 
(37) Faizova, R.; Fadaei-Tirani, F.; Bernier-Latmani, R.; Mazzanti, M. Ligand-Supported Facile Conversion of Uranyl(VI) into Uranium(IV) in Organic and Aqueous Media. Angew. Chem. 2020, 132 (17), $6822-6825$.

(38) Faizova, R.; Scopelliti, R.; Chauvin, A.-S.; Mazzanti, M. Synthesis and Characterization of a Water Stable Uranyl(V) Complex. J. Am. Chem. Soc. 2018, 140 (42), 13554-13557.

(39) Stoliker, D. L.; Kaviani, N.; Kent, D. B.; Davis, J. A. Evaluating Ion Exchange Resin Efficiency and Oxidative Capacity for the Separation of Uranium(IV) and Uranium(VI). Geochem. Trans. 2013, 14 (1), 1.

(40) Wang, X.; Johnson, T. M.; Lundstrom, C. C. Isotope Fractionation during Oxidation of Tetravalent Uranium by Dissolved Oxygen. Geochim. Cosmochim. Acta 2015, 150, 160-170.

(41) Zimina, A.; Dardenne, K.; Denecke, M. A.; Doronkin, D. E.; Huttel, E.; Lichtenberg, H.; Mangold, S.; Pruessmann, T.; Rothe, J.; Spangenberg, Th.; Steininger, R.; Vitova, T.; Geckeis, H.; Grunwaldt, J.-D. CAT-ACT-A New Highly Versatile x-Ray Spectroscopy Beamline for Catalysis and Radionuclide Science at the KIT Synchrotron Light Facility ANKA. Rev. Sci. Instrum. 2017, 88 (11), 113113.

(42) Ravel, B.; Newville, M. ATHENA, ARTEMIS, HEPHAESTUS: Data Analysis for X-Ray Absorption Spectroscopy Using IFEFFIT. J. Synchrotron Radiat. 2005, 12 (Pt 4), 537-541.

(43) Zegke, M.; Zhang, X.; Pidchenko, I.; Hlina, J. A.; Lord, R. M.; Purkis, J.; Nichol, G. S.; Magnani, N.; Schreckenbach, G.; Vitova, T.; Love, J. B.; Arnold, P. L. Differential Uranyl(V) Oxo-Group Bonding between the Uranium and Metal Cations from Groups 1, 2, 4, and 12; a High Energy Resolution X-Ray Absorption, Computational, and Synthetic Study. Chem. Sci. 2019. 109740.

(44) Vitova, T.; Denecke, M. A.; Göttlicher, J.; Jorissen, K.; Kas, J. J.; Kvashnina, K.; Prüßmann, T.; Rehr, J. J.; Rothe, J. Actinide and Lanthanide Speciation with High-Energy Resolution X-Ray Techniques. J. Phys.: Conf. Ser. 2013, 430, 012117.

(45) Sundararajan, M.; Campbell, A. J.; Hillier, I. H. Catalytic Cycles for the Reduction of [UO2]2+ by Cytochrome C7 Proteins Proposed from DFT Calculations. J. Phys. Chem. A 2008, 112 (19), 4451-4457.

(46) Schnaars, D. D.; Wu, G.; Hayton, T. W. Reduction of Pentavalent Uranyl to U(IV) Facilitated by Oxo Functionalization. J. Am. Chem. Soc. 2009, 131 (48), 17532-17533.

(47) Hartshorne, R. S.; Reardon, C. L.; Ross, D.; Nuester, J.; Clarke, T. A.; Gates, A. J.; Mills, P. C.; Fredrickson, J. K.; Zachara, J. M.; Shi, L.; Beliaev, A. S.; Marshall, M. J.; Tien, M.; Brantley, S.; Butt, J. N.; Richardson, D. J. Characterization of an Electron Conduit between Bacteria and the Extracellular Environment. Proc. Natl. Acad. Sci. U. S. A. 2009, 106 (52), 22169-22174.

(48) Ikeda, A.; Hennig, C.; Tsushima, S.; Takao, K.; Ikeda, Y.; Scheinost, A. C.; Bernhard, G. Comparative Study of Uranyl(VI) and -(V) Carbonato Complexes in an Aqueous Solution. Inorg. Chem. 2007, 46 (10), 4212-4219.

(49) Mougel, V.; Pécaut, J.; Mazzanti, M. New Polynuclear U(IV)U(V) Complexes from U(IV) Mediated Uranyl(V) Disproportionation. Chem. Commun. 2012, 48 (6), 868-870.

(50) Nocton, G.; Horeglad, P.; Pécaut, J.; Mazzanti, M. Polynuclear Cation-Cation Complexes of Pentavalent Uranyl: Relating Stability and Magnetic Properties to Structure. J. Am. Chem. Soc. 2008, 130 (49), 16633-16645. 